\title{
ANTHROPOGENIC CHAINGES IN ORGANIC CARBON AND TRACE METAL INPUT TO LAKE WASHINGTON
}

\author{
WR Schel1*, JR Swanson, and LA Currie
}

\author{
National Bureau of Standards \\ Washington, DC 20234
}

ABSTRACT. An example of how man's contaminants are introduced, deposited, and retained in sediments giving a chronological record of events has been developed for Lake Washington, Seattle. Significant amounts of both inorganic and organic compounds in the environment originate from fossil fuel sources, such as power plants and motor vehicles. Many organic compounds are introduced also from contemporary biogenic materials. Through the combined carbon isotope analysis technique (CCIA), we can distinguish between fossil and contemporary carbon sources classes (using ${ }^{14} \mathrm{C}$ ), as we11 as sources within each class (using ${ }^{13} \mathrm{C}$ ). To establish the chronology of the organic carbon pollutant input to the lake sediment, the ages of the layers were determined using $210 \mathrm{pb}$ dating techniques. Sediment profiles of trace metals and a fallout radionuclide plutonium were also obtained and compared with the carbon isotope profiles. The results show that the total organic carbon (TOC) concentration correspond to $93 \%$ modern carbon before 1905. This ${ }^{14} \mathrm{C}$ concentration in TOC decreased to $\sim 60 \%$ modern in the 1930 's and now is between 95 and $80 \%$ modern. The 1ipid fraction is ca $30 \%$ modern and the total aromatic hydrocarbon fraction reached a minimum of $5 \%$ modern in 1954. The large decrease in ${ }^{14} \mathrm{C}$ of TOC around 1930 is believed to be due to coal cust or fly ash. The trace metal concentration also increased substantially at this time. The pattern observed in the sediment thus reflects the change in the local energy consumption pattern from a predominately coal to an oil-based economy. From the plutonium profile we infer that mixing occurs for 3 or 4 years before the sediment layers are compacted.

\section{INTRODUCTION}

One of the key concerns of society is the introduction of large amount of organic compounds into the environment, as we11 as their sources, history, (Hites, LaFlamme and Farrington, 1977) and effects on the ecosystem. The overall impact of

* University of Pittsburgh, Department of Radiological Health, Graduate School of Public Health, Pittsburgh, Pennsylvania 15261 
these organic pollutants often cannot be determined simply by the methods of compound identification by separation and gas chromatography/mass spectrometry as was done for trace metals. The large number of compounds identified by the sophisticated instruments often are confused with those derived from natural oil seeps, coal dust, exometabolites from photosynthesis, and organic degradation products from chemical and bacterial activity. Since many organic compounds are produced and decompose naturally, a means of distinguishing pollution from biogenic chemicals is needed.

\section{ORGANIC-ISOTOPIC METHODS}

Swanson (1980) developed a method to detect anthropogenic pollution and tested it on the chronology of organic pollutants in Lake Washington and Puget Sound. This combined carbon isotope analysis (CCIA) measures $12 \mathrm{C}, 13 \mathrm{C}$, and ${ }^{14} \mathrm{C}$ in carbonaceous compounds found in sediment layers. The total organic carbon, total aliphatic hydrocarbons, and polycyclic aromatic hydrocarbons are separated from kilogram quantities of sediments which have been dated by $210 \mathrm{~Pb}$ methods. The separation steps include freeze drying, extraction, fractionation, column chromatography, and evaporation. A large Soxhlet extraction apparatus is used for the sediment with ultrapure (nanograde) benzene-methanol solution in which $97 \%$ of the total lipids and all hydrocarbons with boiling points higher than that of tetradecane $\left(n-C_{14}\right)$ are extracted. Isolation of the aliphatic and aromatic hydrocarbon fractions is achieved by column chromatography using Sephadex and alumina/silica columns. Combustion and quantitative $\mathrm{CO}_{2}$ measurements (Swanson, 1980) determine the amount of each fraction recovered.

This method is based on natural isotopic differences in organic compounds derived from various sources. Since 1952, al1 carbon that participates in photosynthesis also contains excessive ${ }^{14} \mathrm{C}$, ie, greater than the cosmic-ray-produced level $\left(13.6 \mathrm{dpm} \cdot \mathrm{g}^{-1}\right)$, produced by atomospheric thermonuclear explosions. The CCIA method makes use of these levels of ${ }^{14} \mathrm{C}$ in organic compounds to develop a chronology and a relative biogenic-to-fossil signature of carbon compounds found in sediments. Measurements of ${ }^{12} \mathrm{C}$ and ${ }^{13} \mathrm{C}$ are used also to identify sources of carbon, since isotopic fractionation occurs in photosynthesis and in decomposition processes of organic compounds (Deines, 1980). Thus, the source of a compound can often be distinguised by its $13 \mathrm{C} / 12 \mathrm{C}$ ratio. The 
CCIA method makes use of these isotopic differences together with the ${ }^{14} \mathrm{C}$ content in natural organic compounds (Swanson, 1980). Because of the small amount these organic fractions ( 5 to $10 \mathrm{Mg}$ ) in a reasonable sediment sample size, special lowlevel counting methods must be employed to measure the ${ }^{14} \mathrm{C}$ content. These methods include the use of small quartz counters of 5 to $15 \mathrm{~m}$ volume, rise time pulse shape analysis, and statistical methods of data interpretation for the "few count" region (Davis, Harmer, and Hoffman, 1968; Currie, 1972; Currie, Noakes, and Breites, 1979; Cooper, Currie, and Klouda, 1981). The CCIA method provides data on pollution and the impact of chronic levels of toxicants.

\section{RESULTS AND DISCUSSION}

Figure 1 shows the CCIA method, (B) ${ }^{14} \mathrm{C}$, (C) ${ }^{13} \mathrm{C} /{ }^{12} \mathrm{C}$ isotopic ratio measurements (after Swanson, 1980). The chronology of the sedimentary layers was established using $210 \mathrm{~Pb}$ methods, correlated with known historical time markers, along with trace metal (Fig 1A) and fallout radionuclides (Fig 1D) information (Schell and Barnes, in press). The $14 \mathrm{C}$ profile of total organic carbon (TOC with depth gives ca $100 \%$ modern carbon (based on 0.95 oxalic acid standard of NBS) at the surface layers, decreasing to $63 \%$ at 1930 , then increasing to 95\% modern at 1900 and earlier. To interpret these data, three sources of ${ }^{14} \mathrm{C}$ must be imposed. Prior to 1880 , the Lake Washington area was a pristine forest, with no significant anthropogenic fossil carbon output. The ${ }^{14} \mathrm{C}$ in the $\mathrm{TOC}$ of the sediments reflected the atmospheric or cosmic-ray-produced carbon in organic and inorganic detritus settling to the bottom. The value, $95 \%$ modern (equal to $\sim 400$ years) shows that a small dilution of contemporary carbon does occur, probably due to short storage time ( 400 years) and/or by utilization of lake water $\mathrm{CO}_{2}$ which originates partly from dissolution of carbonate rocks. At ca 1905, a rapid dilution of contemporary ${ }^{14} \mathrm{C}$ in TOC occurred, reaching the greatest dilution of contemporary ${ }^{14} \mathrm{C}$ at ca 1930 . The source of old or fossil carbon then decreased gradually to the present as indicated by the approach to $95 \%$ modern ${ }^{14} \mathrm{C}$. The minimum in the ${ }^{14} \mathrm{C}$ content of TOC at c'a 1930 corresponds to the greatest net dilution by fossil carbon. It is expected that this period corresponds to the maximum particulate carbon input from coal dust, coal burning, or fly ash. This is supported by increased lead and zinc concentrations, shown in figure 1C. Subsequently, natural gas and/or petroleum products were burned; these do not produce as many carbon particles for deposition. Increased ${ }^{14} \mathrm{C}$ in the $1960^{\prime} \mathrm{s}$ and $1970^{\prime} \mathrm{s}$ is not necessarily due 
to decreased fossil carbon input but rather to excessive environmenta $1{ }^{14} \mathrm{C}$ from atmospheric thermonuclear testing.

The upper layers of the sediment contain more ${ }^{14} \mathrm{C}$ than the pre-industrial levels of 90 to $95 \%$. This excess is due to the nuclear weapons tests which produced about one-year equivalent of cosmic-ray produced $14 \mathrm{C}$ for each megaton of nuclear test (Singer, 1962). The first thermonuclear detonation that produced excessive ${ }^{14} \mathrm{C}$ was in 1952; Fig $1 \mathrm{D}$ shows the input of fallout 239, 240 Pu for comparison. The increase in ${ }^{14} \mathrm{C}$ reached a maximum of ca 80 to $100 \%$ excess of modern ${ }^{14} \mathrm{C}$ in 1963 and 1964 (Nyda1, Lovseth, and Gulliksen, 1979), and in 1980, the level decreased to ca $30 \%$ excess of modern at this latitude. Increased fossil carbon since 1952 may be represented by the ${ }^{14} \mathrm{C}$ measurements but the input to the biosphere is a complicated function depending on the nuclear weapons testing schedule and the response of the atmosphere. Thus, because of this source of excessive ${ }^{14} \mathrm{C}$ the upper layers of sediment should give a minimum of fossil-fuel-derived carbon unless appropriate corrections are made. This dilution could be calculated only if comparable ${ }^{14} \mathrm{C}$ measurements were available, eg on surface sediments of a nearby lake which had not experienced pollution effects.

The extractable 1ipid fraction (Fig 1B) illustrates the dilution of biogenic carbon (with a ${ }^{14} \mathrm{C}$ content of 90 to $95 \%$ modern) by carbon compounds from pollution. The value at the 1915 level is already contaminated by fossil carbon at $65 \%$ modern with the greatest contamination at the upper layers of 30 to $40 \%$ modern. The total aliphatic hydrocarbons and polycyclic aromatic hydrocarbons also show the contamination of biogenic carbon by fossil carbon compounds with values in the top 40 years between 9 and 30\% modern (Swanson, 1980).

The ${ }^{13} \mathrm{C} / 12 \mathrm{C}$ ratio $\left(\delta 13 \mathrm{C}_{\mathrm{PDB}}\right)$ in TOC (Fig $1 \mathrm{C}$ ) shows that $\delta^{13} \mathrm{C}$ values of $\mathrm{ca}-270 / 00$ are characteristic of the total organic carbon in sediment before man's impact in 1880 (Swanson, 1980). $\delta^{13} \mathrm{C}$ in organic carbon seems to have increased (became less negative) during the initial clearing of forests in 1280 to 1915 when large increases in sediment deposition occurred. Above 1915, the $\delta^{13} \mathrm{C}$ appears to have decreased up to a surface value of $-29 \%$ o. These more depleted values in the upper region of the layers may be due to increased pollution chemical inputs or perhaps to processes of eutrophication in the water column (Deines, 1980). Extractable lipids measured in the upper layers also show a more depleted trend in $\delta^{13} \mathrm{C}$ although the data are limited. 


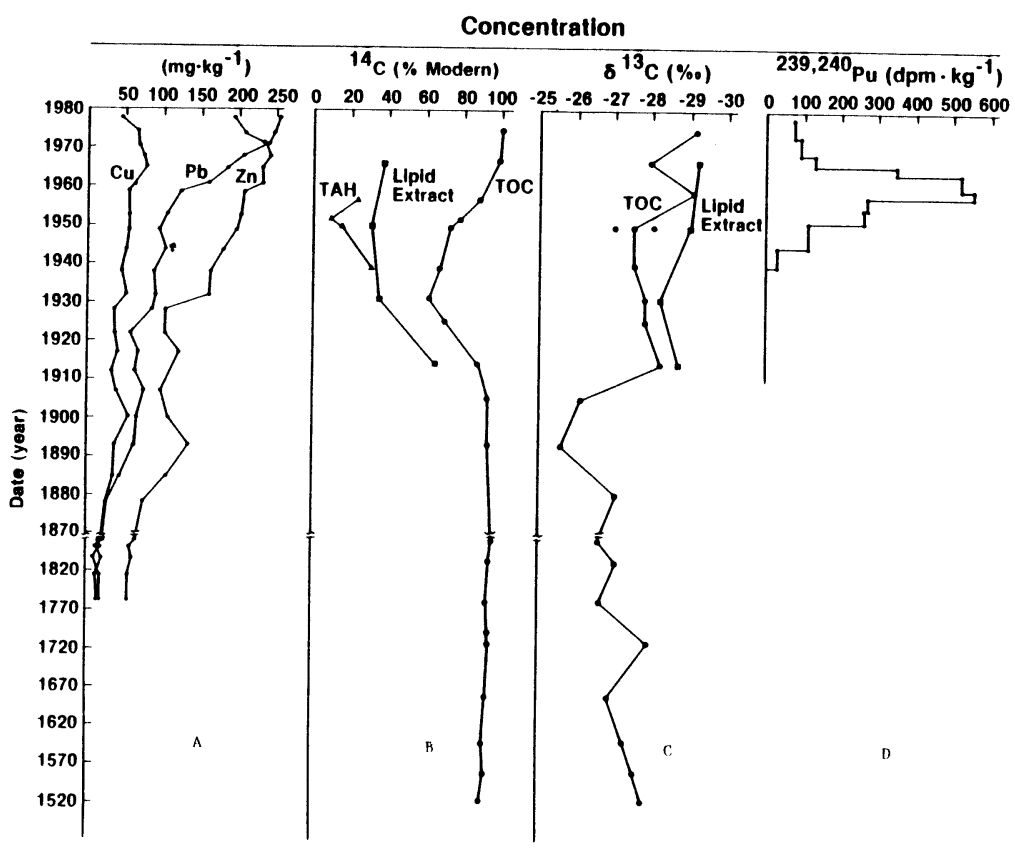

Fig 1. Concentration profiles of trace metals organic carbon and plutonium in Lake Washington as a function of year of sediment deposited at the $62 \mathrm{~m}$ deep station. A. Concentrations of $\mathrm{Cu}, \mathrm{Pb}$, and $\mathrm{Zn}$ with time illustrating anthropotenic sources which contribute to the increase. B. Changes in the organic ${ }^{14} \mathrm{C}$ concentration with time using 0.95 oxalic acid of NBS as standard for $100 \%$ modern. The decrease from the natural biogenic level of 93\% modern ( 400 year old) before 1900 to the minimum in 1930 shows the fossil fuel dilution. TOC is total organic carbon, $\mathrm{TAH}$ is total aromatic hydrocarbon. C. Profiles of the ${ }^{13} \mathrm{C} /{ }^{12} \mathrm{C}$ isotopic ration as a function of depth based on the PDB carbonate standard of $0 \delta^{13}$. Increasing $\delta^{13}$ values from 1890 to 1915 may indicate the contribution of inorganic carbonates to the lake from land erosion. D. Concentrations of $239,240 \mathrm{Pu}$ with time illustrate the fallout from nuclear weapons tests which deposited in the lake. The early 1960's maxima is at the correct time but the presence of plutonium below the 1952 layer shows mixing or diffusion. 
The trend toward smaller $\delta 13 \mathrm{C}$ with decreasing depth illustrates the fact that the isotopically lightest carbon compounds, eg, asphalt and crankcase oil, have diluted the natura1 biogenic carbon isotopic compounds (Deines, 1980). $\delta^{13} \mathrm{C}$ values in biogenic sources of carbon in plankton are all larger than in the surface sediment, eg, Lake Washington plankton - 26\% $\%$, (mostly $\mathrm{C}_{3}$ plants) terrestrial plants $12 \%$ oo (mostly $\mathrm{C}_{4}$ plants) (Swanson, 1980).

The concentration of the total aliphatic hydrocarbon (TAH) fraction extracted from the Lake Washington sediments was measured. The present flux (surface sediment values) of $9 \times 10^{4} \mathrm{~g} \cdot \mathrm{m}^{-2} \cdot \mathrm{yr}^{-1}$ is ca 40 times greater than the flux in 1905 , assuming no degradation (Swanson, 1980). If this flux were due only to fossil carbon, the ${ }^{14} \mathrm{C}$ content of $\mathrm{TAH}$ should be ca $2 \%$ modern. However, the value, 15 to $30 \%$ modern ${ }^{14} \mathrm{C}$, shows that a significant part of the TAH comes from contemporary biogenic carbon and not from coal or oil burning.

The concentrations of the polycyclic aromatic hydrocarbon (PAH) fraction were measured. The present flux of $3 \mathrm{x}$ $10^{3} \mathrm{~g} \cdot \mathrm{m}^{-2} \cdot \mathrm{yr}^{-1}$ is about ten times greater than the flux of $\mathrm{PAH}$ in 1905, assuming no degradation (Swanson, 1980). The ${ }^{14} \mathrm{C}$ content of $10 \%$ modern is about the expected level considering that all the excess PAH comes from fossil fuel (ie, coal and oil).

Fig 1D shows $239,240 \mathrm{Pu}$ measurements in sediment as a function of years of deposition. The layers dated by $210 \mathrm{~Pb}$ fix the time period and the high concentrations of $239,240 \mathrm{Pu}$ in the early 1960 's confirming the chronology determined by $210 \mathrm{~Pb}$. However, the peak concentration of $239,240 \mathrm{Pu}$ is found from 1958 to 1964 , a few years before the maximum fallout peak of 1963 for the northern hemisphere. This time difference may define the "error interval" for mixing of the upper sediment layers at this station. Such a mixing interval of 3 to 4 years may be the time the tracer spends in the upper flocculent layer before final deposition as sediment particles. In addition, $239,240 \mathrm{Pu}$ is found in small but significant concentrations below the 1952 layer when significant levels of radioactive fallout from nuclear weapons tests could not have reached Lake Washington. The depth of penetration to the 1940 layer suggests that plutonium either may be mixed with sediment particles to a significantly deeper level than 3 or 4 years, or that part of the plutonium is not permanently fixed to the sediment particles but diffuse across the deposited layers in the pore water. The diffusion coefficient for plutonium would necessarily be much greater than that of lead in these sediments. Plutonium can 
exist in four possible oxidation states in the aquatic environment: $\mathrm{Pu}(\mathrm{III}), \mathrm{Pu}(\mathrm{IV}), \mathrm{Pu}(\mathrm{V}), \mathrm{Pu}(\mathrm{VI})$. To explain this diffusion in the sediments, we suggest that a portion of the initially deposited plutonium diffuses in the pore water in the form of complexes produced by organic and inorganic chemical reactions occurring during sediment diagenesis. Organic compounds also could diffuse in the pore water resulting in a less-defined maximum with date of the layers.

\section{CONCLUSIONS}

The total aliphatic plus polycyclic aromatic hydrocarbons comprise only ca $14 \%$ of the total carbonaceous compounds in sediment layers (Swanson, 1980). The major fraction, $86 \%$, of the total organic compounds is non-extractable in benzene-methanol and is believed to be coal dust or fly ash. The input of coal dust has decreased from the late 1920's, $40 \%$ of the total organic carbon, to 5 to $20 \%$ at present (Swanson, 1980). This change, which is recorded in the sediments, must reflect the change in the local use pattern of energy consumption from a predominantly coal- to an oil-based economy. The previous atmosphere must have contained much more particulate carbon pollutants than at present.

Concentrations of trace metals ( $\mathrm{Cu}, \mathrm{Pb}, \mathrm{Zn}$ ) in sediments show a trend of increasing enrichment towards the sediment surface with $\mathrm{Pb}$ reaching the highest value of $250 \mu \mathrm{g} / \mathrm{kg}$ at the surface; $\mathrm{Cu}$ and $\mathrm{Zn}$ concentrations decrease at the surface indicating either a decreasing recent input or, more likely, a diffusion of these metals out of the upper layers. The $239,240 \mathrm{Pu}$ concentration profile shows a maximum at about the correct time but also that part of the $239,240 \mathrm{Pu}$ is diffusing and/or mixing to the 1940 level. The quantitative amounts and the history of these contaminants may be found by further interpreting the sedimentary record.

\section{ACKNOWLEDGMENTS}

We would like to acknowledge the assistance of Craig Curro, University of Washington, for the analyses of plutonium in sediments, AW Fairha11, University of Washington, for support in the early laboratory analytical program for ${ }^{14} \mathrm{C}$, and the Gas and Particulate Science Division, Center for Analytical Chemistry, National Bureau of Standards, for the financial support of WR. Schell via an intergovernmental personnel act loan from the University of Washington. 


\section{REFERENCES}

Currie, L A, 1972, The 1imit of precision in nuclear and analytical chemistry: Nuclear Instruments Methods, $\mathrm{v} 100, \mathrm{p}$ 387-395.

Currie, L A, Noakes, J E, and Ereiter, D N, 1979, Measurement of small radiocarbon samples: power of alternative methods for tracing atmospheric hydrocarbons, in Berger, $\mathrm{R}$ and Suess, $\mathrm{H}$ E, eds, Radiocarbon dating, International $14 \mathrm{C}$ conf, 9th, Proc: Berkeley, Univ California Press, p $158-175$.

Cooper, J A, Currie, L A and Klouda G A, 1981, Assessment of contemporary carbon combustion source contributions to urban air particulate levels using carbon-14 measurements: Environmental Sci Technol, v 15, p 1045-1050.

Davis, R, Harmer, D S, and Hoffman, K C, 1968, Search for neutrinos from the sun: Phys Rev Letters, v 20(21), p 1205-1209.

Deines, P, 1980, The isotopic composition of reduced organic carbon: Handbook of environmental isotope geochemistry, Vo1 A, in Fritz, $\mathrm{P}$ and Fontes, JC, eds, The terrestial environment: Amsterdam, New York, Elsevier, p 329-406.

Hites, R A, LaFlamme, R E, and Farrington, J W, 1977. Sedimentary polycyclic aromatic hydrocarbons: The historical record: Science, v 198, p 829-831.

Nyda1, R, Loveseth, K, and Gulliksen, S, 1979, Accuracy of radiocarbon variations in nature since the test ban treaty, in Berger, $\mathrm{R}$ and Suess, $\mathrm{H}$ E, eds, Radiocarbon dating, International ${ }^{14} \mathrm{C}$ conf, $9 \mathrm{th}$, Proc: Berkeley, Univ California Press, p 313-323.

Sche11, W R and Barnes, R S, in press, Environmental isotope and anthropogenic tracers of recent lake sedimentation: Handbook of environmental isotope geochemistry, vol B, in Fritz, P and Fontes, J C, eds, The terrestial environmen Amsterdam, New York, E1sevier in press.

Swanson, J R, (ms) 1980, Carbon isotope analysis of carbonaceous compounds in Puget Sound and Lake Washington: PhD thesis, Univ Washington.

Singer, S F, 1962, Nuclear explosions in space: Nature, v 196, p 307-314. 